Case report

\title{
Intermittent intravenous administration of Iloprost in patients with idiopathic pulmonary arterial hypertension
}

\author{
Majid Malekmohammad ${ }^{a}$, Babak Sharif-Kashani ${ }^{\mathrm{b}, *}$, Fateme Monjazebi ${ }^{\mathrm{c}}$, Leila saliminejad ${ }^{\mathrm{c}}$ \\ a Tracheal Disease Research Center, NRITLD, Masih Daneshvari Hospital, Shahid Beheshti University of Medical Sciences,Tehran, Iran

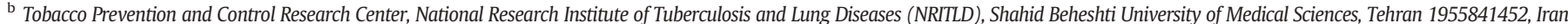 \\ c Chronic Respiratory Diseases Research Center, National Institute of Tuberculosis and Lung Diseases (NRITLD), Shahid Beheshti University of Medical Sciences, Tehran, Iran
}

\section{A R T I C L E I N F O}

\section{Article history:}

Received 12 May 2016

Received in revised form 4 June 2016

Accepted 6 June 2016

Available online 11 June 2016

\section{Keywords:}

Iloprost

Idiopathic pulmonary arterial hypertension

Intermittent Intravenous

\begin{abstract}
A B S T R A C T
Background and objectives: Because there is no cure for idiopathic pulmonary artery hypertension (IPAH), improving survival and stabilizing disease are key aims in any treatment strategy for patients with IPAH. Intravenous (IV) administration of prostacyclin positively affects the symptoms and hemodynamic of patients with IPAH.

This study sought to assess the efficacy of cyclic Iloprost administration in Iranian patients with IPAH.

Materials and methods: This longitudinal study was conducted on 20 patients with IPAH. Upon hospitalization, the patients received intermittent IV administration of Iloprost 6 hours a day for 5 days; this cycle was repeated every 6 weeks, total duration of treatment was 12 months. New York Heart Association/World Health Organization (NYHA/WHO) functional classification (FC), 6-minute walk test (6MWT), mean pulmonary arterial pressure (PAPm), right ventricular pressure (RVP), and serum level of N-terminal pro b-type natriuretic peptide (NT-proBNP) were assessed at baseline, during and after completion of treatment course. The data were analyzed using SPSS version 13.

Results: The FC, PAPm, and RVP significantly decreased after the treatment $(\mathrm{P}<0.001)$. No change occurred in the level of oxygen saturation during the 6MWT but the distance walked significantly increased after the intervention compared to baseline. Level of NT-proBNP significantly decreased in patients after treatment $(\mathrm{P}=0.009)$. Conclusion: Intermittent IV administration of Iloprost decreases the FC, PAPm, RVP, and serum level of NT-proBNP and increases the distance walked in the 6MWT by patients.

(C) 2016 The Society of Cardiovascular Academy. Production and hosting by Elsevier B.V. All rights reserved. This is an open access article under the CC BY-NC-ND license (http://creativecommons.org/licenses/by-nc-nd/4.0/).
\end{abstract}

\section{Introduction}

Pulmonary hypertension $(\mathrm{PH})$ refers to an increase in mean pulmonary arterial pressure (PAPm) $\geq 25 \mathrm{mmHg}$ as assessed by right heart catheterization (RHC). ${ }^{1}$ This condition can be idiopathic, congenital, or acquired, related to diseases and conditions such as connective tissue diseases, congenital heart disease, portal hypertension, AIDS, and some toxins and medications such as appetite suppressing drugs; PAH does not have a good prognosis. ${ }^{2-4}$ Idiopathic pulmonary artery hypertension is a rare disorder with an unknown etiology, in which occlusion of small pulmonary arteries increases the PAPm and results in secondary right ventricular insufficiency. ${ }^{5}$ The prevalence of PAH in the United States varies from 4.5 to 12.3 per 100,000 population. ${ }^{1}$ In Europe, its prevalence has been reported to be 15-60 patients per one

\footnotetext{
* Corresponding author. Tel.:+98 2127122499; fax: +98 2126106003.

E-mail addresses: mmalekmohammad@yahoo.com (M. Malekmohammad),

babaksharifkashani@yahoo.com (B. Sharif-Kashani),fmonjazebi@gmail.com

(F. Monjazebi), saliminejad.af85@yahoo.com (L. saliminejad).

Peer review under responsibility of The Society of Cardiovascular Academy.
}

million individuals. ${ }^{6-7}$ In the UK, the prevalence of PAH is 97 per one million. ${ }^{1}$ The prevalence of $\mathrm{PAH}$ is 15 per one million, and the prevalence of IPAH is 5.9 per one million population in France. ${ }^{8}$ Approximately $50 \%$ of PAH patients in all registries suffer from IPAH, heritable PAH, or druginduced PAH. ${ }^{1}$ Thus, it can be estimated that among the 77 -million population of Iran, 150 subjects develop PAH annually. ${ }^{1}$ Considering the survival rate of 1-2 years (without treatment), approximately 400 450 patients in Iran suffer from IPAH. The statistics of patients registered in the referral centers are close to this value taking into account some related factors. Before the development of new medications, the mean survival rate of patients with PAH was less than 3 years. ${ }^{2}$

Medications such as oxygen, calcium channel blockers, warfarin, digoxin, and diuretics have long been used for these patients as part of conventional therapy. These medications are selected based on the current treatment protocols for chronic cardiac and respiratory diseases and based on the pathophysiological mechanism proposed for the left heart congestive failure, hypoxia in patients with obstructive pulmonary diseases, and systemic hypertension and are referred to as symptomatic treatment. ${ }^{5}$ Calcium channel blockers (CCB) must be prescribed only for patients with a positive response to vasodilator test; these patients 
require precise follow-up and may need some specific treatments. ${ }^{6,9}$ Medications recently recommended for these patients include endothelin receptor antagonists (ERAs), soluble guanylate cyclase stimulators such as riociguat, phosphodiesterase type 5 inhibitors (PDE-5I) such as sildenafil, and prostanoids such as epoprostenol and Iloprost. ${ }^{10-11}$

In patients with positive vasodilator test, who are categorized as low-risk group based on clinical examinations, CCB is the first choice of treatment. If CCB do not improve the patient's condition, specific treatment with oral ERAs such as bosentan or PDE-5Is such as sildenafil may be started. For low-risk patients with a negative vasodilator test, treatment with one of the specific medications is started. ${ }^{1}$ For high-risk patients with a negative test, continuous treatment with IV prostacyclin can be effective; in such cases, epoprostenol, treprostinil, or Iloprost is the first choice of treatment. ${ }^{12}$

Prostacyclin (PGI2) is a strong vasodilator, which prevents the proliferation of endothelial smooth muscle cells; however, the synthesis of prostacyclin decreases in IPAH. ${ }^{11}$ Evidence shows that administration of IV prostacyclin along with conventional treatments for more than 12 weeks can positively affect exercise capacity, FC, and hemodynamic of cardiovascular patients. ${ }^{13}$ Prostacyclin is an important homeostasis regulator and is a strong short-acting prostanoid produced in the vascular endothelium. Iloprost- $\beta$-cyclodextrin clathrate, also known as Iloprost, is a synthetic, chemically strong, and stable prostacyclin. ${ }^{14-15}$ Iloprost is an analog of epoprostenol, also known as prostacyclin (PGI2), which mimics the pharmaceutical properties of epoprostenol. It prevents platelet aggregation in vessels, causes vascular dilation, and enhances the blood flow through the vessels; thus, it also prevents polycythemia. ${ }^{14,16}$ This drug can be administered via three routes of oral, inhalation, and injection. ${ }^{11}$

This drug is most commonly administered intravenously. ${ }^{16}$ Intravenous administration of Iloprost requires hospitalization since patients should be monitored for the side effects of the drug during administration such as tachycardia, hypotension, ${ }^{17}$ headache, and flushing. ${ }^{16}$ Iloprost and epoprostenol are chemically similar with the exception that Iloprost is more stable, readily available, and easier for use at home. ${ }^{18}$ Iloprost decreases the resistance of peripheral vessels and the mean arterial pressure while it increases the cardiac index and heart rate. Also, it increases the renal blood flow ${ }^{19}$ but has a natriuretic effect and increases the excretion of sodium in urine; however, this is independent of the related hemodynamic changes. ${ }^{16}$ The clearance of this drug is $15-20 \mathrm{~mL} / \mathrm{kg} / \mathrm{min}$ and has a half-life of 5-20 min. Most of it (70\%) is excreted through the kidneys and $12-17 \%$ is excreted via other routes. ${ }^{15}$ To obtain an effective plasma level, it must be continuously infused in an amount of $1-2 \mathrm{ng} / \mathrm{kg} / \mathrm{min} .{ }^{19}$ By introduction of new medications such as epoprostenol and Iloprost, 1 -year and 3-year survival rates of patients increased by $68-88 \%{ }^{20}$

Iloprost is administered in IPAH patients in two forms of continuous ${ }^{21}$ and intermittent or cyclic infusion. ${ }^{12}$ Continuous infusion requires adequate vascular access obtained by insertion of a permanent catheter in the subclavian vein and the drug is delivered to the patient by CADD1 infusion pumps. The drug is administered with the initial infusion rate of $0.5 \mathrm{ng} / \mathrm{kg} / \mathrm{min}$, which is gradually increased as long as no unbearable side effects occur. After hospital discharge, patients are visited in an outpatient setting every 6-12 weeks. In case of satisfactory clinical outcomes (based on the opinions of the attending physician and patients), the drug dosage does not change. In case of no change or aggravation of disease, the drug dosage increases unless unbearable side effects occur. Each patient visit must include history taking, physical examination, and 6MWT along with functional assessment using $\mathrm{FC}^{22}$ In intermittent or cyclic infusion, Iloprost is administered for five consecutive days for 6 hours a day. This cycle is repeated every 6 weeks. The initial infusion rate is $0.5 \mathrm{ng} / \mathrm{kg} / \mathrm{min}$, which later increases to $2 \mathrm{ng} / \mathrm{kg} / \mathrm{min}$. ${ }^{9,12}$

Following the initiation of treatment, its outcome must be evaluated in patients. Several tools are available for outcome assessment in IPAH patients such as echocardiography, assessment of hemodynamic parameters, ${ }^{23}$ 6MWT, ${ }^{24}$ biochemical markers such as serum uric acid, ${ }^{25-26} \mathrm{FC},{ }^{27}$ and NT-proBNP. ${ }^{28}$ Echocardiography is a noninvasive method suitable for primary and outcome assessments of treatment in these patients. This modality provides valuable information about the hemodynamic status of the right heart such as PAPm, status of the right and left ventricles, and atriums. ${ }^{29-31}$ The 6MWT is affordable, simple, reproducible, standard, and objective ${ }^{24}$ and has been introduced as the gold standard for the assessment of the treatment outcome in PAH patients by the European Agency for Evaluation of Medicinal Products and the Food and Drug Administration. ${ }^{32-33}$ The 6MWT is the most important criterion for assessment of treatment outcome and severity of disease in patients in the clinical setting and in clinical trials for research purposes. ${ }^{34}$ The level of NT-proBNP increases in IPAH patients by a reduction in the right ventricular function. ${ }^{35}$ Studies show that in patients with PAH, the level of NT-proBNP is correlated to the functional ${ }^{28}$ and hemodynamic ${ }^{36}$ status of patients and can be used as a predictor of the survival of patients. ${ }^{35,37}$

Considering the high cost of prostacyclin medications ${ }^{18}$ particularly in Iran, patients often cannot afford continuous treatment with this medication. Thus, patients who require IV prostacyclin according to the guidelines can only receive this drug in a cyclic fashion by hospitalization for 5 days per month and repeat this cycle every 6 weeks. No previous study has assessed the outcome and efficacy of cyclic administration of Iloprost in IPAH patients and the available ones have only focused on connective tissue diseases. Therefore, this study sought to assess the outcome and efficacy of cyclic treatment with Iloprost in Iranian patients with IPAH.

\section{Materials and methods}

This longitudinal study was conducted during 2011-2013 on patients presenting to Masih Daneshvari Hospital due to mean pulmonary artery pressure (mPAH). Only 20 patients during the above-mentioned time period required treatment with IV Iloprost. The inclusion criteria were definite diagnosis of IPAH based on right ventricular catheterization and the expert opinions of the cardiologists and pulmonologists of Masih Daneshvari Hospital, the need for treatment with IV Iloprost, and willingness for participation in the study. Data were collected using a researcherdesigned questionnaire. This questionnaire included demographic information (age, sex, height, and weight of patients and duration of disease), FC, 6MWT (distance walked and drop in 02 saturation), echocardiographic findings (PAPm and RVP), hemodynamics on right ventricular catheterization (PAPm and atrial pressure), and level of NT-proBNP at baseline, in the first 6 weeks, in the second 6 weeks, and in the third 6 weeks of the study. The demographic part of the questionnaire was filled out by interviewing patients and the sections regarding clinical and paraclinical tests were filled out by the research supervisor based on the opinions of cardiologists and pulmonologists of Masih Daneshvari Hospital. The validity and reliability of these clinical and paraclinical tests have been assessed in several studies and the 6MWT is also known as the gold standard for assessment of patients with IPAH. ${ }^{32,34}$ These tests are routinely performed for assessment of the course of treatment in IPAH patients hospitalized in Masih Daneshvari Hospital. After explaining the objectives of the study to patients, written informed consent was obtained from them. Patients were informed that they were free to leave at any time and that not participating in this study would not affect their course of treatment. Also, patients were ensured about the confidentiality of their information. Each patient

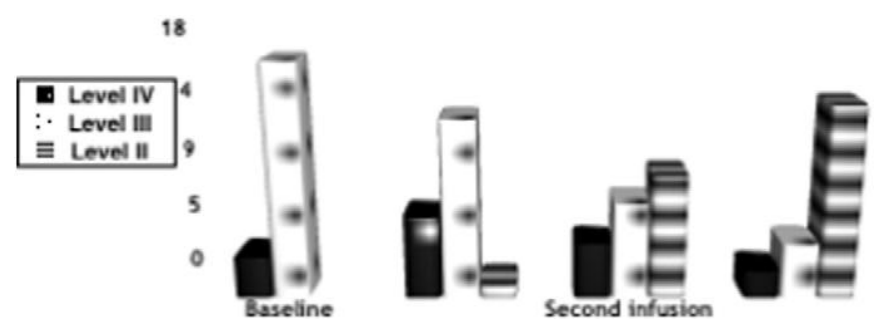

Diagram 1. Changes in the FC of patients following treatment. 
Table 1

Demographic factor and base line characteristics.

\begin{tabular}{|c|c|c|c|c|c|c|c|}
\hline $\mathrm{n}$ & Gender & Age & $\begin{array}{l}\text { NYHA } \\
\text { class }\end{array}$ & $\begin{array}{l}\text { PAP } \\
\text { cath }\end{array}$ & $\begin{array}{l}\text { PAP } \\
\text { echo }\end{array}$ & NT-proBNP & 6MWT \\
\hline 1 & $\mathrm{~F}$ & 27 & III & 75 & 75 & 760 & 538 \\
\hline 2 & $\mathrm{~F}$ & 37 & III & 80 & 80 & 854 & 423 \\
\hline 3 & $\mathrm{~F}$ & 30 & III & 85 & 90 & 208 & 375 \\
\hline 4 & $\mathrm{~F}$ & 38 & IV & 100 & 110 & 2250 & 183 \\
\hline 5 & $\mathrm{~F}$ & 37 & III & 95 & 95 & 1940 & 247 \\
\hline 6 & $\mathrm{~F}$ & 45 & III & 75 & 80 & 1264 & 305 \\
\hline 7 & $\mathrm{~F}$ & 28 & IV & 100 & 110 & 3280 & 195 \\
\hline 8 & $\mathrm{~F}$ & 27 & III & 90 & 95 & 1672 & 453 \\
\hline 9 & $\mathrm{~F}$ & 41 & III & 65 & 80 & 960 & 310 \\
\hline 10 & $\mathrm{~F}$ & 43 & III & 95 & 95 & 845 & 341 \\
\hline 11 & $\mathrm{~F}$ & 35 & III & 70 & 80 & 1250 & 275 \\
\hline 12 & $\mathrm{~F}$ & 37 & IV & 110 & 110 & 4783 & 175 \\
\hline 13 & $\mathrm{~F}$ & 28 & III & 65 & 85 & 1760 & 257 \\
\hline 14 & $\mathrm{~F}$ & 32 & IV & 110 & 120 & 7413 & 154 \\
\hline 15 & $\mathrm{~F}$ & 34 & III & 60 & 65 & 1452 & 196 \\
\hline 16 & $\mathrm{~F}$ & 31 & IV & 120 & 120 & 5340 & 60 \\
\hline 17 & $\mathrm{~F}$ & 34 & III & 95 & 90 & 986 & 327 \\
\hline 18 & $\mathrm{~F}$ & 24 & III & 65 & 80 & 705 & 231 \\
\hline 19 & $\mathrm{~F}$ & 40 & III & 85 & 85 & 604 & 510 \\
\hline 20 & $\mathrm{~F}$ & 32 & III & 75 & 80 & 965 & 192 \\
\hline
\end{tabular}

presenting to Masih Daneshvari Hospital with PAH was routinely examined and treated. Prior to treatment, the questionnaire was filled out for patients requiring IV Iloprost who gave their written informed consent for participation in this study; IV Iloprost was then administered according to the protocol. The intermittent or cyclic protocol includes IV administration of Iloprost for five consecutive days for 6 hours daily. In this study, after hospitalization, the patients received IV Iloprost 6 hours a day for 5 days and then every 6 weeks after discharge. The initial infusion rate was $0.5 \mathrm{ng} / \mathrm{kg} / \mathrm{min}$ at first, which was then increased to $2 \mathrm{ng} / \mathrm{kg} / \mathrm{min}$. The dose titrated up as long as no unbearable side effects occur within $2 \mathrm{~h}$ of Iloprost infusion. All of these patients also received $50 \mathrm{mg}$ sildenafil daily and $125 \mathrm{mg}$ bosentan twice daily during the study period. During the course of treatment, serum level of NT-proBNP was measured at each hospitalization. Echocardiography and FC were assessed. After the third injection, patients performed the 6MWT for assessment of functional capacity. The data were analyzed using SPSS version 13 and repeated-measures ANOVA, Friedman test, and the Pearson's correlation coefficient.

\section{Results}

All patients were females with a mean age of $34 \pm 5.8$ years. The mean height of patients was $160 \pm 5 \mathrm{~cm}$, the mean weight was $61 \pm$ $14 \mathrm{~kg}$, and the duration of disease was $3 \pm 1$ years.

The results of cardiac catheterization showed that the PAPm was $85.75 \pm 17 \mathrm{mmHg}$ and the right atrial pressure was $14 \pm 3 \mathrm{mmHg}$ before treatment. Before the IV administration of Iloprost, 75\% of patients were FC III and $25 \%$ were FC IV. While after treatment with IV Iloprost, $70 \%$ of patients were FC II, $20 \%$ were FC III, and 10\% were FC IV. Diagram 1 shows changes in the FC of patients compared to baseline. The Friedman test showed that the FC of patients significantly decreased compared to baseline $(\mathrm{P}<0.001)$.
Diagram 1 shows echocardiographic changes in PAPm and RVP of patients. Repeated-measures ANOVA showed that PAPm and RVP of patients significantly decreased in post-treatment echocardiography.

The results also showed that the maximum and minimum distance walked was 538 and $60 \mathrm{~m}$, respectively, in the 6MWT. Table 2 shows the mean and standard deviation of the distance walked in the 6MWT and the reduction in oxygen saturation rate during the test and at the end of study compared to baseline. As seen, no change was noted with regard to reduction in oxygen saturation during the test. However, walked distance at the end of study increased compared to baseline. (See Table 1.) (See Table 3.)

The highest and the lowest levels of NT-proBNP were $7413 \mathrm{pg} / \mathrm{mL}$ and $208 \mathrm{pg} / \mathrm{mL}$, respectively, at baseline with a mean value of $1964 \pm$ $1760 \mathrm{pg} / \mathrm{mL}$. At the end of study, level of NT-proBNP increased in 5 patients (25\%) and decreased in 15 patients (75\%) compared to baseline. Diagram 2 shows the changes in NT-proBNP during the study. Repeatedmeasures ANOVA showed that the level of NT-proBNP in patients significantly decreased post-treatment $(P=0.009)$.

\section{Discussion}

Based on the results, intermittent IV administration of Iloprost effectively decreased FC, PAPm, RVP, and level of NT-proBNP and increased the distance walked in the 6MWT but blood oxygen saturation were not changed. Functional class is among the most important indicators of prognosis in patients with $\mathrm{PAH}$. It has also been used in preliminary studies for assessment of the course of treatment in patients. ${ }^{27}$ Higenbottam et al. showed that FC is among the most important predictors of $\mathrm{PAH}$ especially in class III and IV patients compared to class I and II subjects who receive Iloprost or epoprostenol for long periods of time. ${ }^{18}$ Prior to the initiation of treatment with Iloprost, most patients had FC III and IV. But after intermittent treatment with Iloprost, many patients improved to FC. The PAPm is another predictor of disease status. The results of our study showed that the mean PAPm decreased in patients receiving intermittent IV infusion of Iloprost for long periods of time. Caravita et al. reported that long-term intermittent IV infusion of Iloprost in patients with connective tissue diseases decreased PAPm, inhibited PAH, and prevented the aggravation of disease. ${ }^{9}$ Caramaschi et al. evaluated the efficacy of cyclic IV infusion of Iloprost to prevent PAH in patients with systemic sclerosis and reported that cyclic infusion of Iloprost for 15 months prevented PAH in these patients. ${ }^{12}$ Bartman et al. showed that cyclic infusion of Iloprost prevented PAH in patients with systemic sclerosis. ${ }^{38}$ Niewierowicz et al. in $1995^{39}$ and Bartosik et al. in 1996 evaluated the efficacy of cyclic infusion of Iloprost for treatment of $\mathrm{PAH}$ in a number of patients with systemic sclerosis and reported the same results. ${ }^{40}$ In all these studies, echocardiography was used to monitor the patients' status and PAPm. In contrast, Higenbottam et al., in their study, stated that the mean PAPm especially in patients receiving prostaglandin was not a suitable predictor of disease status or the course of treatment. $^{18}$

Although the pulmonary vascular resistance ${ }^{2,41}$ and the mean pressure of the right atrium are among the most important predictors of disease status and course of treatment in patients with $\mathrm{PAH},{ }^{27,41}$ their measurement requires right heart catheterization. In the current study similar to some previous investigations, ${ }^{9,12,38,40}$ right heart catheterization was performed for patients at baseline to confirm the diagnosis. To

Table 2

Changes in PAPm and RVP.

\begin{tabular}{|c|c|c|c|c|c|c|c|c|c|c|}
\hline \multirow[t]{2}{*}{ Time points } & \multirow[t]{2}{*}{ Variable } & \multicolumn{2}{|c|}{ Baseline } & \multicolumn{2}{|c|}{ First infusion } & \multicolumn{2}{|c|}{ Second infusion } & \multicolumn{2}{|c|}{ Third infusion } & \multirow[t]{2}{*}{ Repeated-measures ANOVA } \\
\hline & & Mean & Sd & Mean & Sd & Mean & Sd & Mean & $\mathrm{Sd}$ & \\
\hline \multirow[t]{2}{*}{ Echocardiography } & PAPm & 91 & 25 & 90 & 22 & 85 & 21 & 81 & 22 & $\mathrm{P}<0.001$ \\
\hline & $R V P$ & 88 & 26 & 88 & 20 & 84 & 20 & 80 & 22 & $P=0.050$ \\
\hline Catheterization & $P A P m$ & 85.75 & 17 & - & - & - & - & - & - & \\
\hline
\end{tabular}


monitor the patients' status, echocardiography and assessment of PAPm were done. Echocardiography is a non-invasive method for primary assessment of the course and outcome of treatment and provides valuable information regarding the hemodynamics of the right heart. ${ }^{29,31}$ It should be noted that each diagnostic procedure should be done based on the opinions of the experts and the patient's need. New guidelines on the control and treatment of PAH clearly state that repeat of cardiac catheterization is only allowed if the patient's condition has worsened or a modification has occurred in the type of treatment administered. ${ }^{1}$ Since the condition of none of the patients in our study was worsened and there was no need to change the type of drug, repeat of right heart catheterization was not ethical.

In the 6MWT, no change was noted with regard to oxygen saturation rate during the test $(\mathrm{P}=0.244)$. However, the distance walked in the 6MWT significantly increased post-treatment compared to baseline $(\mathrm{P}<0.001)$. Caravita et al. showed significant increase in the distance walked in the 6MWT after IV infusion of Iloprost. ${ }^{9}$

Although the level of NT-proBNP decreased in only $75 \%$ of patients compared to baseline, statistical tests indicated a significant reduction in level of NT-proBNP in patients $(P=0.009)$. Evidence shows that in PAH, level of NT-proBNP is related to the functional status ${ }^{28}$ and hemodynamics ${ }^{36}$ of patients and it can be used as a predictor of survival of patients. ${ }^{35,37}$ The results of studies in this regard indicate that in patients with $\mathrm{PAH}$, the level of NT-proBNP has a strong inverse correlation with right ventricular insufficiency, and the plasma level of NT-proBNP is a predictor of mortality in these patients. The results of previous studies have also shown that patients with NT-proBNP $\geq$ $150 \mathrm{pg} / \mathrm{mL}$ have lower survival rates. ${ }^{35}$ In the study by Caravita et al., a significant correlation was noted between PAPm and serum level of NT-proBNP; NT-proBNP and PAPm were also reported to have a significant reverse correlation with the distance walked in the 6MWT. ${ }^{9}$

\section{Conclusion}

The results of this study showed that intermittent IV administration of Iloprost in patients with PAH decreased the FC, PAPm, RVP, and level of NT-proBNP and increased the distance walked in the 6MWT. Since the palliative care has not been well addressed in the PAH literature, intermittent IV administration of Iloprost can be as the palliative care in IPAH with FC III and IV.

\section{Limitation}

The effect of treatment can not only be explained by the Iloprost, because all of these patients also received sildenafil and bosentan during the study period and ethically we could not stop basic treatment of patients. Also patients were followed only with echocardiography because none of our patient's condition has worsened and no modification has occurred in the type of treatment administered.

\section{Source of funding}

This study was funded by a grant from the National Research Institute of Tuberculosis and Lung Diseases (NRITLD), Shahid Beheshti University of Medical Sciences, Tehran, Iran.

Table 3

Comparison of the results of 6MWT at baseline and at the end of study

\begin{tabular}{|c|c|c|c|c|c|}
\hline \multirow{2}{*}{$\begin{array}{l}\text { Time } \\
\text { Variable }\end{array}$} & \multicolumn{2}{|c|}{ Baseline } & \multicolumn{2}{|c|}{ End of study } & \multirow[t]{2}{*}{ Paired t-test } \\
\hline & Mean & Sd & Mean & Sd & \\
\hline Distance walked in meters & 287 & 124 & 351 & 114 & $\mathrm{p}<0 / 001$ \\
\hline Reduction in oxygen saturation & 7 & 8 & 6 & 4 & $\mathrm{P}=0 / 244$ \\
\hline
\end{tabular}

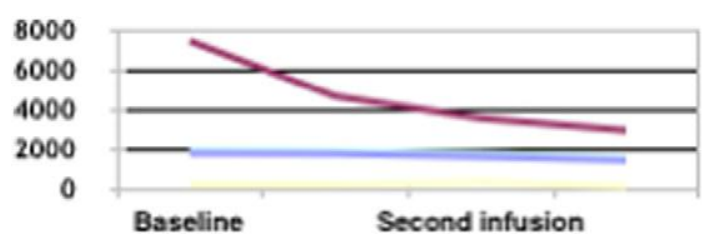

Diagram 2. Changes in the mean level of NT-proBNP following treatment.

\section{Financial/nonfinancial disclosures}

The authors have no significant conflicts of interest that exist with any companies/organizations whose products or services may be discussed in this article.

\section{Acknowledgment}

This research project was approved by the National Research Institute of Tuberculosis and Lung Disease, Masih Daneshvari Hospital, in 2012. The authors would like to thank the research deputy of the hospital and the physicians and personnel of the intensive care unit, patients, and their family members for their sincere cooperation.

We want to thank the C.C.U. staff for their help in data collection.

\section{References}

1. Task FM, Galiè N, Humbert M, et al. 2015 ESC/ERS Guidelines for the diagnosis and treatment of pulmonary hypertension: the Joint Task Force for the Diagnosis and Treatment of Pulmonary Hypertension of the European Society of Cardiology (ESC) and the European Respiratory Society (ERS) Endorsed by: Association for European Paediatric and Congenital Cardiology (AEPC), International Society for Heart and Lung Transplantation (ISHLT). Eur Heart J 2015.

2. D'Alonzo GE, Barst RJ, Ayres SM, et al. Survival in patients with primary pulmonary hypertension: results from a national prospective registry. Ann Intern Med 1991;115(5): 343-349.

3. Galiè N, Rubin LJ. Introduction: new insights into a challenging disease. A review of the third world symposium on pulmonary arterial hypertension. J Am Coll Cardiol 2004;43(12s1) [S1-S].

4. Simonneau G, Galie N, Rubin LJ, et al. Clinical classification of pulmonary hypertension. J Am Coll Cardiol 2004;43(12s1):S5-S12.

5. Humbert M, Sitbon O, Simonneau G. Treatment of pulmonary arterial hypertension. N Engl J Med 2004;351(14):1425-1436.

6. Galiè N, Hoeper MM, Humbert M, et al. Guidelines for the diagnosis and treatment of pulmonary hypertension. The Task Force for the Diagnosis and Treatment of Pulmonary Hypertension of the European Society of Cardiology (ESC) and the European Respiratory Society (ERS), endorsed by the International Society of Heart and Lung Transplantation (ISHLT). Eur Heart J 2009;30(20):2493-2537.

7. Peacock A, Murphy N, McMurray J, Caballero L, Stewart S. An epidemiological study of pulmonary arterial hypertension. Eur Respir J 2007;30(1):104-109.

8. Humbert M, Sitbon O, Chaouat A, et al. Pulmonary arterial hypertension in France: results from a national registry. Am J Respir Crit Care Med 2006;173(9):1023-1030.

9. Caravita S, Wu SC, Secchi MB, Dadone V, Bencini C, Pierini S. Long-term effects of intermittent Iloprost infusion on pulmonary arterial pressure in connective tissue disease. Eur J Intern Med 2011;22(5):518-521.

10. Galiè N, Corris PA, Frost A, et al. Updated treatment algorithm of pulmonary arterial hypertension. J Am Coll Cardiol 2013;62(25 S).

11. Humbert M, Morrell NW, Archer SL, et al. Cellular and molecular pathobiology of pulmonary arterial hypertension. J Am Coll Cardiol 2004;43(12s1):S13-S24.

12. Caramaschi P, Volpe A, Tinazzi I, Bambara LM, Carletto A, Biasi D. Does cyclically Iloprost infusion prevent severe isolated pulmonary hypertension in systemic sclerosis? Preliminary results. Rheumatol Int 2006;27(2):203-205.

13. Paramothayan NS, Lasserson TJ, Wells A, Walters EH. Prostacyclin for Pulmonary Hypertension in Adults. The Cochrane Library; 2005.

14. Gryglewski R, Stock G. Prostacyclin and Its Stable Analogue Iloprost. Springer; 1987.

15. Krause W, Krais T. Pharmacokinetics and pharmacodynamics of the prostacyclin analogue iloprost in man. Eur J Clin Pharmacol 1986;30(1):61-68.

16. Grant SM, Goa KL. Iloprost Drugs 1992:43(6):889-924

17. Janssena M, Wollersheim H, Kraus C, Hildebrand M, Watson H, Thien T. Pharmacokinetics of oral iloprost in patients with Raynaud's phenomenon secondary to systemic sclerosis. Prostaglandins Other Lipid Mediat 2000:60(4):153-160.

18. Higenbottam T, Butt A, McMahon A, Westerbeck R, Sharples L. Long term intravenous prostaglandin (epoprostenol or iloprost) for treatment of severe pulmonary hypertension. Heart 1998;80(2):151-155.

19. Magnani B, Galie N. Prostacyclin in primary pulmonary hypertension. Eur Heart J 1996;17(1):18-24.

20. Hildebrand M, Pfeffer M, Mahler M, Staks T, Windt-Hanke F, Schütt A. Oral iloprost in healthy volunteers. Eicosanoids 1990;4(3):149-154. 
21. McLaughlin VV, Shillington A, Rich S. Survival in primary pulmonary hypertension the impact of epoprostenol therapy. Circulation 2002;106(12):1477-1482.

22. Rich S, Rubin L, Abenhail L. Executive summary from the World Symposium on Primary Pulmonary Hypertension (Evian, France, September 6-10, 1998). The World Health Organization publication via the Internet Available at: http://www.who.int/ncd/cvd/ pph.html.

23. McLaughlin VV, Presberg KW, Doyle RL, et al. Prognosis of pulmonary arterial hypertension* ACCP evidence-based clinical practice guidelines. CHEST J 2004;126(1_suppl): 78S-92S.

24. Laboratories ACoPSfCPF. ATS statement: guidelines for the six-minute walk test. Am J Respir Crit Care Med 2002;166(1):111.

25. Bendayan D, Shitrit D, Ygla M, Huerta M, Fink G, Kramer M. Hyperuricemia as a prognostic factor in pulmonary arterial hypertension. Respir Med 2003;97(2):130-133.

26. Voelkel MA, Wynne KM, Badesch DB, Groves BM, Voelkel NF. Hyperuricemia in severe pulmonary hypertension. CHEST J 2000;117(1):19-24.

27. Higenbottam T, Spiegelhalter D, Scott J, et al. Prostacyclin (epoprostenol) and heart-lung transplantation as treatments for severe pulmonary hypertension. $\mathrm{Br}$ Heart J 1993;70(4):366-370.

28. Leuchte HH, Holzapfel M, Baumgartner RA, et al. Clinical significance of brain natriuretic peptide in primary pulmonary hypertension. J Am Coll Cardiol 2004;43(5):764-770.

29. Badesch DB, Abman SH, Ahearn GS, et al. Medical therapy for pulmonary arterial hypertensionACCP evidence-based clinical practice guidelines. CHEST J 2004;126(1_suppl):35S-62S.

30. Badesch DB, Champion HC, Sanchez MAG, et al. Diagnosis and assessment of pulmonary arterial hypertension. J Am Coll Cardiol 2009;54(1s1):S55-S66.

31. McLaughlin VV, Archer SL, Badesch DB, et al. ACCF/AHA 2009 Expert Consensus Document on Pulmonary Hypertension. A report of the American College of Cardiology Foundation Task Force on Expert Consensus Documents and the American Heart Association Developed in Collaboration With the American College of Chest Physicians;
American Thoracic Society, Inc.; and the Pulmonary Hypertension Association. J Am Coll Cardiol 2009;53(17):1573-1619.

32. Palange $\mathrm{P}$, Ward $\mathrm{S}$, Carlsen $\mathrm{K}$, et al. Recommendations on the use of exercise testing in clinical practice. Eur Respir J 2007;29(1):185-209.

33. Society AT, Physicians ACoC. ATS/ACCP Statement on cardiopulmonary exercise testing. Am J Respir Crit Care Med 2003;167(2):211.

34. Hoeper MM, Oudiz RJ, Peacock A, et al. End points and clinical trial designs in pulmonary arterial hypertensionClinical and regulatory perspectives. J Am Coll Cardiol 2004;43(12s1):S48-S55

35. Nagaya N, Nishikimi T, Uematsu M, et al. Plasma brain natriuretic peptide as a prognostic indicator in patients with primary pulmonary hypertension. Circulation 2000;102(8):865-870.

36. Souza R, Bogossian H, Humbert M, et al. N-terminal-pro-brain natriuretic peptide as a haemodynamic marker in idiopathic pulmonary arterial hypertension. Eur Respir 2005;25(3):509-513.

37. Nagaya N, Nishikimi T, Okano Y, et al. Plasma brain natriuretic peptide levels increase in proportion to the extent of right ventricular dysfunction in pulmonary hypertension. J Am Coll Cardiol 1998;31(1):202-208.

38. Bartram S, Denton C, du Bois R, Black C. Use of intravenous prostacyclin to treat pulmonary hypertension associated with systemic sclerosis. Br J Rheumatol 1994;33( suppl 1):30.

39. Niewierowicz I, Eskilsson J, Scheja A, Akesson A. Intermittent iloprost infusion therapy for pulmonary hypertension in scleroderma-a pilot study. Scand J Rheumatol 1995;24: 123-127.

40. Bartosik I, Eskilsson J, Scheja A, A A. Intermittent iloprost infusion therapy of pulmonary hypertension in scleroderma-a pilot study. Br J Rheumatol 1996;35:1187-1190.

41. Fuster V, Steele P, Edwards W, Gersh B, McGoon M, Frye R. Primary pulmonary hypertension: natural history and the importance of thrombosis. Circulation 1984;70(4):580-587. 